$\$$ Research Square

\title{
Rehabilitation For Life: The Effect On Physical Function of Rehabilitation And Care In Older Adults After Hip Fracture: Study Protocol For a Cluster-Randomised Stepped-Wedge Trial
}

\author{
Jonas Ammundsen Ipsen ( $\square$ jonas.ammundsen.ipsen@rsyd.dk) \\ Sygehus Lillebælt Kolding Sygehus: Sygehus Lillebalt Kolding Sygehus https://orcid.org/0000-0002-1650-0531 \\ Lars T. Pedersen \\ University College South Denmark: UC Syddanmark \\ Bjarke Viberg \\ Policlinic of Modena Department of Orthopedic Surgery and Traumatology, University Hospital of Southern Denmark \\ Birgitte Nørgaard \\ University of Southern Denmark Institute for Public Health: Syddansk Universitet Institut for Sundhedstjenesteforskning \\ Charlotte Suetta \\ Department of geriatric and palliative Medicine, Bispebjerg og Frederiksberg hospital, university of Copenhagen \& Department og Medicine \\ Herlev and Gentofte Hospitals University of Copenhagen \\ Inge Hansen Bruun \\ department og physical therapy and occupational therapy Lillebaelt Hospital and Department of Regional Health Research, University of \\ Southern Denmark
}

\section{Research Article}

Keywords: hip fracture, rehabilitation, care, between sectors, empowerment and physical function

Posted Date: September 20th, 2021

DOl: https://doi.org/10.21203/rs.3.rs-386636/v1

License: @ (i) This work is licensed under a Creative Commons Attribution 4.0 International License. Read Full License 


\section{Abstract}

Background: A hip fracture is a serious event for older adults, given that approximately $50 \%$ do not regain their habitual level of physical function, and the mortality rate is high, as is the number of readmissions. The gap in healthcare delivery, as separated into two financial and self-governing sectors, might be a contributing cause of inferior rehabilitation and care for these patients. Therefore, we aim to assess the effect of continuous and progressive rehabilitation and care across sectors for older adults after hip fracture.

Methods/design: The project is designed as a stepped-wedge cluster-randomised controlled trial. The study population of patients are older adults 65 years of age and above discharged after a hip fracture and healthcare professionals in primary and secondary care (municipalities and hospitals). In addition, health care professionals from different sectors (hospital and municipalities) will be engaged in the empowerment-orientated praxis, through a workshop for health care professionals with knowledge sharing to the older adults using a digital health application (app). The rehabilitation intervention consists of 12 weeks progressive resistance exercises initiated 1-2 days after discharge. To improve communication across sectors, a videoconference involving the patient and physiotherapists from both sectors, will be conducted.

At Day 3 after discharge, an outreach nurse performs a thorough assessment including measurement of vital signs. A hotline to the hospital for medical advice is a part of the intervention. The intervention is delivered as an add-on to the usual rehabilitation and care, and it involves one regional hospital and the municipalities within the catchment area of the hospital.

The primary outcome is a Timed Up and Go test eight weeks post-surgery

Discussion: Using a stepped-wedge design, the intervention will be assessed as well as implemented in hospital and municipalities, hopefully for the benefit of older adults after hip fracture. Furthermore, the collaboration between the sectors is expected to improve.

The study is approved by the Regional Scientific Ethics Committees of Southern Denmark (S-20200070) and the Danish Data Protection Agency (20-21854). Clinical Trial Identifier (NCT04424186) https://clinicaltrials.gov/ct2/show/NCT04424186.

\section{Background}

A hip fracture is a serious event for older adults since approximately $50 \%$ do not regain their habitual level of physical function thus, acquiring new or additional need for care $(1,2)$. Furthermore, when compared to an age-matched group the one-year mortality is increases threefold and the quality of life is reduced $(2,3)$. The 30 -day readmission rate after a hip fracture is as high as $16-19 \%(4,5)$.

For older adults, it is well-known that poor mobilisation and reduced activity during and after hospitalisation trigger loss of muscle mass which leads to increased mortality (3) and fatigue (6-9). To reduce mortality, early detection of illness and complications has been shown to be important, as has sufficient pain management $(10,11)$. Insufficient pain management has been found to increase the risk of complications, morbidity, and mortality and also impede physical activity (12). Nevertheless, continuous and progressive rehabilitation, as well as the detection of critical illness and complications, are lacking across the sectors in a healthcare system divided into two financial and self-governing sectors.

In Denmark, average length of stay is 5-7 days for hip fracture patients (11). Rehabilitation in the primary sector must be initiated within seven days after discharge. However, usual care does not include systematic assessment including vital signs measurement. Furthermore, various exercise regimes are used depending on sectors and the regimes are usually not specified in terms of intensity or progression (13). Communication and cooperation between sectors is also lacking, although the older adults express a need for increased involvement (14).

To impede functional decline and lower mortality and readmission rates, continuous and progressive rehabilitation and care across sectors is needed. This study introduces an empowerment-orientated praxis focusing on continuous rehabilitation and care, as well as optimised communication and cooperation between sectors.

\section{Aim}

This study aims to assess the effect of continuous and progressive rehabilitation and care across sectors for older adults following a hip fracture.

\section{Methods}

\section{Trial Design}


The protocol describes a cluster-randomised stepped-wedge trial. It has a superiority design, a 1:1 allocation ratio and the time interval for each step is set to three months, as illustrated in Figure 1. The study protocol follows the Standard Protocol Items: Recommendations for Interventional trial the SPIRIT checklist was used, see additional files $(15,16)$. A trial registration dataset is reported in Table 1.

\section{Trial setting}

The trial will involve a regional hospital in Denmark and the municipalities in the hospital's catchment area, all of them serving a mixed urban and rural population. Two of the municipalities will be divided into two clusters to account for the unequal population size. Services within hospitals and municipalities are free of charge in Denmark, and the responsibility for rehabilitation is shared between sectors (17). At the time of discharge, older adults with a medically assessed need for rehabilitation are offered a referral for municipal rehabilitation (17).

\section{Eligibility criteria}

The trial will include older adults 65 years of age and older, admitted to the ortho-geriatric ward with a hip fracture and residing in one of the municipalities. Other inclusion criteria are patients orientated in time and place, able to speak and understand Danish. Patients discharged to permanent residence in nursing homes or patients with competing diseases disabling relevant conversation, such as progressed dementia, or receiving palliative care, will be excluded.

\section{Usual rehabilitation and care in the primary and secondary sectors}

After admission to the emergency department, patients with a hip fracture are transferred to an ortho-geriatric ward. During hospitalisation, the patients are examined by an orthopaedic surgeon and a geriatric specialist. Mobilisation and rehabilitation are initiated within 24 hours post-surgery and performed along with vital signs measurement for the early detection of critical illness and complication, throughout the entire hospitalisation period. A physiotherapist is responsible for rehabilitation which comprises walking, exercise and an instruction to a selftraining programme. The Cumulated Ambulation Score (CAS) (18) is assessed daily and the need for walking aids is continuously evaluated. The rationale for usual praxis during admission is that early mobilisation and exercise, as well as early detection of critical illness, provide an optimal basis for regaining walking ability and reducing mortality.

In the primary sector, rehabilitation can involve single professions or be interdisciplinary and can take place in the patient's own home or at a rehabilitation centre. The majority of patients with a hip fracture receive activity-based rehabilitation, e.g. gait, walking on stairs, and sit-tostand at home, typically twice a week for 6-8 weeks. Care in the primary sector follows the plan prescribed by the hospital. Any treatment changes have to be prescribed by the general practitioner.

In the municipalities, restorative care is used to restore and maintain activities of daily living (ADL). The older adults' motivation for rehabilitation is obtained by using the ADL tasks they wish to be able to carry out as an exercise.

\section{Intervention}

The intervention will be offered to the intervention group in addition to the usual exercise and care. The intervention is comprehensive and includes rehabilitation, empowerment and care. The duration of the intervention will be 12 weeks (post-surgery). The basis for the intervention is that continuous and progressive rehabilitation, as well as early detection of critical illness and complication during and after hospitalization, will improve the older adults' physical performance. The older adults are expected to be motivated by an empowermentorientated praxis (19).

Within the first two weeks after discharge, rehabilitation in the primary sector comprises five rehabilitation sessions. This will be followed by supervised rehabilitation twice a week for another 10 weeks. The rehabilitation in both sectors will follow a progressive rehabilitation programme including resistance exercise. Progression of resistance follows the national guideline for hip fractures which suggest resistance is added at 3 sets of 15 unweighted repetitions and progresses to 3 sets of 8 repetitions maximum (11). For patients with a CAS $\geq 4$, rehabilitation in a municipal rehabilitation centre will be recommended; alternatively, the resistance exercises will be performed at home with wrist weights. Except for the sit to stand exercise, the older adults will be requested to perform the exercises as often as possible, preferably three times a week. The exercise sit-to-stand as many times as possible will be recommended after each of the three main meals a day (20).

In the municipalities, nurses will visit the older adults on the third day after discharge to measure vital signs. Vital signs consist of early detection of illness or complications and pain management, e.g. blood pressure, pulse, respiratory frequency, saturation, consciousness, 
temperature and saturation combined with measurement of C-reactive protein and haemoglobin.

An empowerment-orientated practice requires a change in the healthcare professionals' approach towards seeing the older adults as a partner capable of acting and taking responsibility (21). To implement the empowerment-orientated praxis, two initiatives are used: first, the patients will be given access to knowledge (21). The older adults will receive a training suitcase containing the rehabilitation regime, training equipment, and a guide to a digital healthcare app. The app contains videos and informative interviews with doctors and nurses from the ortho-geriatric ward and health professionals from the municipalities $(22,23)$. Second, health professionals will participate in a workshop where they will learn about empowerment and how to use it. During the workshop, the health professionals will also be informed on the importance of strength training and measuring vital signs and pain and introduced to the rehabilitation regime. The intervention is described using the Template for Intervention Description and Replication (TIDieR) (24) Table 2.

\section{Primary outcomes}

The primary outcome for physical function is Timed Up and Go (TUG) eight weeks after discharge As the study is organised across two sectors the CAS score measured 30 days after discharge makes a second primary outcome (25).

TUG is a valid and reliable test that measures the time it takes a person to get up from a chair with an armrest, walk three meters, return to the chair, and sit (26). The standard error of measurement (SEM) for patients with hip fractures is $11 \%$ (13). It is hypothesised that patients in the intervention group will achieve a significantly reduced TUG score compared to usual care.

The CAS assesses mobility by a) getting in and out of bed, b) sit to stand c) gait with a usual walking aid. It is hypothesised that a significantly larger number of patients in the intervention group will have a CAS $=6$ at 30 days post-surgery compared to the control.

\section{Secondary outcomes}

Physical Function will also be measured using New Mobility Score (NMS, 0-9), and the 30-sec sit-to-stand test (30s-CST). The NMS assesses the patients' gait inside, outside, and during shopping (27) and the 30s-CST is a valid test that assesses lower body strength (28, 29).

Activities of daily living will be measured using Barthel-20 (0-20), which is a validated tool used to assess the patients' need for help to perform activities of daily living $(30,31)$.

\section{Other Outcomes}

Physical Function is measured using Handgrip Strength (HGS) which is a biomarker for ageing (32).

Activities of daily living will be measured using Composite Physical Function (CPF, 0-24). CPF assesses the patients' need for help to basic and instrumental activities of daily living (33).

Pain will be assessed using the four-point Verbal Rating Scale (VRS, no pain, slight pain, moderate pain, and severe pain)(34).

Readmission will be measured 30 days after discharge

Mortality will be assessed as an event 30 days after discharge and within the first year.

Quality of life and Pain will be measured using the EuroQol five-dimension questionnaire (EQ-5D). EQ-5D is a standardised questionnaire, used to assess the patients' health-related quality of life and function (35).

Empowerment will be assessed using the Patient Activation Measure (PAM)(36). PAM includes thirteen questions addressing prevention and lifestyle changes.

Fatigue will be assessed using the Brief Fatigue Inventory (BFI) (37).

Collaboration between health professionals will be assessed using a questionnaire designed by Joint Action Analytics to measure relational capacity (38) The questionnaires will be distributed before workshops and three months after the workshop.

Costs information will be collected for a cost-utility analysis (39). Data from registries, municipalities and hospitals is gathered retrospectively while information on carers' and volunteers' expenses in assisting the older adult in activities of daily living is gathered 
prospectively.

Costs information and information on the number of supervised training sessions, activity level, pain, place of rehabilitation and the number of self-training sessions will be collected every two weeks for 12 weeks. The patients will be equipped with a diary as a memory aid.

\section{Participant timeline}

A timeline and a description of the specific data collected at each time point are presented in Table 3.

\section{Sample size}

The annual enrolment of patients with hip fractures to the specific hospital is approximately 335 . Of these, presumably $55 \%$ will meet the inclusion criteria equivalent to nine patients per cluster every quarter. Up to $20 \%$ are expected to drop out due to frailty. Based on these assumptions, it is expected that approximately seven patients per cluster will be recruited every three months for the trial. With five clusters the expected inclusion period is 18 months.

The power calculation for the TUG is based on a reduction on 25\% (40) and an estimated TUG score at discharge on $21.1 \mathrm{sec}(9.2)(41,42)$. Power $=89 \%$ Interclass coefficient $($ ICC) $=0.01$ and a 0.05 .

For CAS the power calculation is based on a $30 \%$ increase in the proportion of older adults who, 30 days post-surgery have a CAS score $=6$, power $=90 \%$.

\section{Recruitment}

All older adults admitted to the ortho-geriatric ward will be assessed for inclusion consecutively by project assistants who are also responsible for obtaining informed consent.

\section{Allocation}

Randomisation will be performed by opening a sequentially numbered opaque envelope every three months. A person with no patient contact and unfamiliar with the project will undertake this job. The envelopes will be prepared in advance using a balanced internet-based randomisation list (43).

Blinding is not possible as the health professionals need to know the older adults who are citizens in a municipality randomised to intervention. Due to the visibility of intervention, this is not possible to the assessor either. Only health professionals in the primary sector assigned for the workshop will have contact with the older adults assigned for intervention. Also, at the time of the procedure, they will ensure that the collection of data at admission and eight weeks later is not performed by the same project assistant, and the same applies for the following collection of data.

\section{Data collection}

Data collectors collect data at 8 weeks, 12 weeks, and 6 months through home visits. Inter-rater reliability will be investigated. In case of dropout, the reason for this will be examined.

\section{Data management}

All data will be stored on secured servers in the region of Southern Denmark and data will be entered prospectively.

\section{Statistical analysis}

In the descriptive analyses, intervention and controls will be described and compared to assess homogeneity. Categorical variables will be compared using chi-square tests and student's t-test or log-rank test will be used for continuous variables depending on the distribution (normal or not). 
The analyses of outcomes follow the intention-to-treat principle. Missing outcomes will be imputed with multiple imputation (44). For nonadherence to protocol, non-response analyses will be performed for excluded patients and non-completers. A per-protocol analysis will be conducted as a sensitivity analysis.

The effect of the intervention for continuous variables will be assessed using a linear mixed model with a random effect for each cluster and a fixed effect for each step of the stepped wedge model.

Categorical and ordinal data will be analysed using either a logistic or an ordinal logistic model. The experiences of the healthcare professional will be examined with a paired student's t-test.

As an ancillary analysis, differences in effect pending on clusters will be examined.

\section{Discussion}

The project aims to improve physical function in older patients after hip fracture. It is hypothesised that patients in the intervention group will gain a significantly improved physical function compared to patients following usual care.

Besides the above-mentioned improved physical function, it is important to accentuate that the study operates across sectors and organisational conditions on which the design is based. A clear advantage of the cluster-randomised stepped-wedge design is the implementation of the intervention at the end of the trial municipalities and hospital. By randomising in clusters and introducing incremental rollout, issues such as impaired organisational commitment should be met (45). Furthermore, the design has been used in previous trials working in the primary and secondary sectors $(45,46)$. At the end of the project, the intervention is implemented offering a manual for how interventions may be implemented in other hospitals and municipalities (47). A drawback of the design is the risk of unequal exposure to seasonal trends.

The implementation of the intervention might pose some challenges due to the needed organisational changes. Therefore, a pilot test is performed to acquire experience on how the intervention is delivered. Furthermore, procedures to monitor the delivery of the intervention have been set up, in terms of structured telephone interviews every two weeks. We expect the physical presence of the training suitcase will help empower patients and health professionals. Data on older patients' activity levels and function enable the evaluation of possible associations between functional improvement and an increase in the level of activity.

\section{Trial Status}

Protocol version number 1 10.11.2020. Initiation of recruitment 01.10.2020 approximate recruitment completion date 01.04.2022. Is case of significant amendments an updated version with data and version number will be published.

\section{Declarations}

\section{Ethics approval and consent to participate}

The study is approved by the Regional Scientific Ethics Committees of Southern Denmark (S-20200070) and the Danish Data Protection Agency (20-21854). As required by Danish legislation, written informed consent will be obtained from participants to permit the collection of information from medical records. ClinicalTrials.gov Identifier: (NCT04424186). Results will be disseminated through peer-reviewed journals and other media. Responsibility of trial conduct is shared between authors.

\section{Consent for publication}

Not applic1able

\section{Availability of data and materials}

Data sharing does not apply to this article as no datasets were generated or analysed during the current study.

Exercise regimes, consent forms, further descriptions, etc. can be acquired from corresponding author. 


\section{Competing interests}

The authors declare that they have no competing interests

Sponsors does not have influence on the conduct or reporting of trial.

\section{Funding}

The project is funded by the National Association of Municipalities, the Region of Southern Denmark, the Association of Danish Physiotherapists, and the Research Council of Lillebaelt Hospital - University Hospital of Southern Denmark, Denmark.

\section{Authors' contributions}

IHB led the coordination and conceptualizing of the trial, supported by BV, BN, and CS. JAI wrote the first draft of the article supported by IHB. IHB, BV, BN, LTP and CS critically reviewed it and provided comments to improve the manuscript. All authors read and approved the final manuscript.

All contributors to the protocol is represented by the authors.

\section{Acknowledgments}

We gratefully acknowledge the municipalities of Kolding, Vejle, Vejen, Billund and Middelfart and the ortho-geriatric ward at Lillebaelt Hospital for input and willingness and eager to participate in the project.

\section{References}

1. Bertram M, Norman R, Kemp L, Vos T. Review of the long-term disability associated with hip fractures. Injury prevention : journal of the International Society for Child and Adolescent Injury Prevention. 2011;17(6):365-70.

2. Dyer SM, Crotty M, Fairhall N, Magaziner J, Beaupre LA, Cameron ID, et al. A critical review of the long-term disability outcomes following hip fracture. BMC geriatrics. 2016;16:158.

3. Carpintero P, Caeiro JR, Carpintero R, Morales A, Silva S, Mesa M. Complications of hip fractures: A review. World J Orthop. 2014;5(4):40211.

4. de Luise C, Brimacombe M, Pedersen L, Sorensen HT. Comorbidity and mortality following hip fracture: a population-based cohort study. Aging clinical and experimental research. 2008;20(5):412-8.

5. Dansk Tværfagligt Register for Hoftenære Lårbensbrud (RKKP) Århus: Afdeling for hjerte/kar, kirurgi og Akutområdet, Regionernes Klinisk Kvalitetsudviklingsprogram.; 2018 [Available from: https://www.sundhed.dk/content/cms/62/4662_dansk-tvaerfaglig-register-for-hoftenaerelaarbensbrud.pdf.

6. Helleso R, Lorensen M, Sorensen L. Challenging the information gap--the patients transfer from hospital to home health care. International journal of medical informatics. 2004;73(7-8):569-80.

7. Danish Health Authority. Håndbog i Rehabiliteringsforløb på ældreområdet 2016 [[Guidelines for rehabilitation of older adults ]:[Available from: https://www.sst.dk/da/Feeds/ /media/6D27215F08464CA0A68E949BBA4BD23B.ashx.

8. Puggaard L, Andersen-Ranberg K, Kronborg C, Højgaard B, Hoff M. En undersøgelse af trænings-og genoptræningsindsatsen fra indlæggelse til egen bolig-gråzone-problematikken [Internet ]. Copenhagen2006 [updated Janury 10 2014. [An examination of exercise and rehabilitation efforts from hospitalization to own home: the grey area problem, National Board of Social Services]. Available from:

http://www.google.dk/url?

sa $=$ t\&rct=j\&q=\&esrc=s\&frm=1\&source=web\&cd=4\&ved=0CDsQFjAD\&url=http\%3A\%2F\%2Fwww.socialstyrelsen.dk\%2Faeldre\%2Fforebyggelseog-sundhed\%2Ffiler\%2FEnundersgelseaftrningsoggenoptrningsindsatsen.pdf\&ei=yIRBUoXSB4HnswaW6YH4BQ\&usg=AFQjCNEbwdewn1K9tGcZ94SWjj8a2CX4A\&bvm=bv.52434380,d.Yms. 
9. Mistiaen P, Duijnhouwer E, Wijkel D, de Bont M, Veeger A. The problems of elderly people at home one week after discharge from an acute care setting. Journal of advanced nursing. 1997;25(6):1233-40.

10. Patientombuddet. Temarapport om observation af patienter på sygehuse [rapport rettet mod ledelse og plajepersonale ]. patietnsombuddet patientombuddet 2014 [Available from: https://stps.dk/da/udgivelser/2014/temarapport-om-observation-af-patienter-paasygehuse/ /media/E1CF165CDAA345C3ADA7A0DBBE2B73D8.ashx.

11. Danske Regioner. Lærings- og Kvalitetetsteams, Hoftenære lårbensbrud 2019 [Available from: https://kvalitetsteams.dk/laerings-ogkvalitetsteams/lkt-hoftenaere-laarbensbrud.

12. Prowse M. Postoperative pain in older people: a review of the literature. Journal of clinical nursing. 2007;16(1):84-97.

13. Kronborg L, Bandholm T, Kehlet H, Kristensen MT. Municipality-based physical rehabilitation after acute hip fracture surgery in Denmark. Danish medical journal. 2015;62(4):A5023.

14. Jensen CM, Smith AC, Overgaard S, Wiil UK, Clemensen J. "If only had I known": a qualitative study investigating a treatment of patients with a hip fracture with short time stay in hospital. International journal of qualitative studies on health and well-being. 2017;12(1):1307061.

15. Chan A-W, Tetzlaff JM, Altman DG, Laupacis A, Gøtzsche PC, Krleža-Jerić K, et al. SPIRIT 2013 statement: defining standard protocol items for clinical trials. Ann Intern Med. 2013;158(3):200-7.

16. Chan A-W, Tetzlaff JM, Gøtzsche PC, Altman DG, Mann H, Berlin JA, et al. SPIRIT 2013 explanation and elaboration: guidance for protocols of clinical trials. BMJ : British Medical Journal. 2013;346:e7586.

17. socialministeriet S-oæob-o. vejledning om genoptræning og vedligeholdelses træning i kommuner og regioner sundhedsstyrelsen Sundhed- og ældreministeriet 2018 [cited 2020 12.08]. Available from: https://www.sst.dk/da/udgivelser/2018/vejledning-om-genoptraeningog-vedligeholdelsestraening-i-kommuner-og-regioner.

18. Aagaard P, Suetta C, Caserotti P, Magnusson SP, Kjaer M. Role of the nervous system in sarcopenia and muscle atrophy with aging: strength training as a countermeasure. Scand J Med Sci Sports. 2010;20(1):49-64.

19. Rasmussen B, Nielsen CV, Uhrenfeldt L. Being active $1 \frac{1}{2}$ years after hip fracture: a qualitative interview study of aged adults' experiences of meaningfulness. BMC geriatrics. 2020;20(1):263.

20. Joanisse S, Lim C, McKendry J, McLeod JC, Stokes T, Phillips SM. Recent advances in understanding resistance exercise training-induced skeletal muscle hypertrophy in humans. 2020;9.

21. Wahlin I. Empowerment in critical care - a concept analysis. Scandinavian journal of caring sciences. 2017;31(1):164-74.

22. Jensen CM, Overgaard S, Wiil UK, Clemensen J. Can Tele-Health Support Self-Care and Empowerment? A Qualitative Study of Hip Fracture Patients' Experiences With Testing an “App”. SAGE Open Nursing. 2019;5:2377960819825752.

23. Jensen CM, Overgaard S, Wiil UK, Smith AC, Clemensen J. Bridging the gap: A user-driven study on new ways to support self-care and empowerment for patients with hip fracture. SAGE Open Medicine. 2018;6:2050312118799121.

24. Hoffmann TC, Glasziou PP, Boutron I, Milne R, Perera R, Moher D, et al. Better reporting of interventions: template for intervention description and replication (TIDieR) checklist and guide. BMJ (Clinical research ed). 2014;348:g1687.

25. Kristensen MT, Jakobsen TL, Nielsen JW, Jorgensen LM, Nienhuis RJ, Jonsson LR. Cumulated Ambulation Score to evaluate mobility is feasible in geriatric patients and in patients with hip fracture. Danish medical journal. 2012;59(7):A4464.

26. Hvid LG, Suetta C, Nielsen JH, Jensen MM, Frandsen U, Ortenblad N, et al. Aging impairs the recovery in mechanical muscle function following 4 days of disuse. Experimental gerontology. 2014;52:1-8.

27. Kristensen MT, Bandholm T, Foss NB, Ekdahl C, Kehlet H. High inter-tester reliability of the new mobility score in patients with hip fracture. Journal of rehabilitation medicine. 2008;40(7):589-91.

28. Jones CJ, Rikli RE, Beam WC. A 30-s chair-stand test as a measure of lower body Ssrength in community-residing older adults. Research quarterly for exercise and sport. 1999;70(2):113-9. 
29. Bruun IH, Mogensen CB, Nørgaard B, Schiøttz-Christensen B, Maribo T. Validity and responsiveness to change of the 30-second ChairStand Test in older adults admitted to an emergency department. Journal of Geriatric Physical Therapy. 2017;00:1-10.

30. Maribo T, Lauritsen JM, Waehrens E, Poulsen I, Hesselbo B. Barthel Index for evaluation of function: a Danish consensus on its use. Ugeskrift for laeger. 2006;168(34):2790-2.

31. Pedersen TJ, Lauritsen JM. Routine functional assessment for hip fracture patients. Acta orthopaedica. 2016;87(4):374-9.

32. Bohannon RW. Grip Strength: An Indispensable Biomarker For Older Adults. Clinical interventions in aging. 2019;14:1681-91.

33. Rikli RE, Jones CJ. The Reliability and Validity of a 6-Minute Walk Test as a Measure of Physical Endurance in Older Adults. Journal of Aging and Physical Activity. 1998;6(4):363-75.

34. Bech RD, Lauritsen J, Ovesen O, Overgaard S. The Verbal Rating Scale Is Reliable for Assessment of Postoperative Pain in Hip Fracture Patients. Pain research and treatment. 2015;2015:676212.

35. EuroQol Research Foundation. EQ-5D 1987 [updated June 18 2017. Available from: https://euroqol.org/eq-5d-instruments/.

36. Maindal HT, Vedsted P, Mikkelsen EM. Oversættelse og kulturel tilpasning af den danske version af „The Patient Activation Measure“. Klinisk Sygepleje. 2011;25(1):7-17.

37. Shuman-Paretsky MJ, Belser-Ehrlich J, Holtzer R. Psychometric properties of the Brief Fatigue Inventory in community-dwelling older adults. Archives of physical medicine and rehabilitation. 2014;95(8):1533-9.

38. Analytics JA. relationel kapacitet https://www.jointactionanalytics.dk/ydelser/2020 [

39. Drummond MF. Methods for the economic evaluation of health care programmes. 3. ed. Oxford: Oxford University Press; 2007.

40. Stasi S, Papathanasiou G, Chronopoulos E, Dontas IA, Baltopoulos IP, Papaioannou NA. The Effect of Intensive Abductor Strengthening on Postoperative Muscle Efficiency and Functional Ability of Hip-Fractured Patients: A Randomized Controlled Trial. Indian journal of orthopaedics. 2019;53(3):407-19.

41. Kristensen MT, Henriksen S, Stie SB, Bandholm T. Relative and absolute intertester reliability of the timed up and go test to quantify functional mobility in patients with hip fracture. Journal of the American Geriatrics Society. 2011;59(3):565-7.

42. Poulsen KL. Optimering af tværsektoriel genoptræning efter hoftebrud- erfaringer, tips og tricks fra et tværsektorielt samarbejde. 3 Læringsseminar - LKT Hoftenære Lårbensbrud Denmark 2019.

43. envelope S. Randomisation and online databases for clinical trials 2001 [updated October 2020. Available from: https://www.sealedenvelope.com/simple-randomiser/v1/new.

44. Sterne JAC, White IR, Carlin JB, Spratt M, Royston P, Kenward MG, et al. Multiple imputation for missing data in epidemiological and clinical research: potential and pitfalls. BMJ (Clinical research ed). 2009;338:b2393.

45. Rasmussen CDN, Holtermann A, Mortensen OS, Søgaard K, Jørgensen MB. Prevention of low back pain and its consequences among nurses' aides in elderly care: a stepped-wedge multi-faceted cluster-randomized controlled trial. BMC Public Health. 2013;13(1):1088.

46. Toftegaard BS, Bro F, Vedsted P. A geographical cluster randomised stepped wedge study of continuing medical education and cancer diagnosis in general practice. Implement Sci. 2014;9:159-.

47. Grimshaw JM, Ivers N, Linklater S, Foy R, Francis JJ, Gude WT, et al. Reinvigorating stagnant science: implementation laboratories and a meta-laboratory to efficiently advance the science of audit and feedback. BMJ Quality \&amp;amp; Safety. 2019;28(5):416.

\section{Tables}

Table 1. trial registration data 


\begin{tabular}{|c|c|}
\hline Data category & Information \\
\hline $\begin{array}{l}\text { Primary registry and trial identifying } \\
\text { number }\end{array}$ & CliniCaltrial.gov NCT04424186 \\
\hline $\begin{array}{l}\text { Date of registration in primary } \\
\text { registry }\end{array}$ & 09.06.2020 \\
\hline $\begin{array}{l}\text { Source(s) of monetary or material } \\
\text { support }\end{array}$ & Lillebaelt Hospital - University Hospital of Southern Denmark \\
\hline Primary sponsor & Lillebaelt Hospital - University Hospital of Southern Denmark \\
\hline Secondary sponsor(s) & Municipalities in the catchment area \\
\hline Contact for public queries & IHB JAI (Email) \\
\hline Contact for scientific queries & IHB JAI (Email) \\
\hline Public titel & 'Rehabilitation for Life' \\
\hline Scientific title & $\begin{array}{l}\text { Rehabilitation for life: the effect on physical function of rehabilitation and care in older adults } \\
\text { after hip fracture }\end{array}$ \\
\hline Countries of recruitment & Region of southern Denmark \\
\hline $\begin{array}{l}\text { Health condition(s) or problem(s) } \\
\text { studied }\end{array}$ & Hip fractures in older adults \\
\hline \multirow[t]{2}{*}{ Key inclusion and exclusion criteria } & Inclusion: older adults (>65) admitted to orthogeriatric ward with a hip fracture \\
\hline & Exclusion: terminal, inability to communicate (dementia) og resident in elder care center \\
\hline Study type & cluster-randomized stepped-wedge trial clinical trial \\
\hline Date of first enrolment & October 2020 \\
\hline Target sample size & 330 \\
\hline Recruitment status & Recruiting \\
\hline Primary outcome(s) & Timed Up and Go and Cumulated ambulation score \\
\hline Key secondary outcomes & 30 sec chair to Stand test, new mobility score and Barthel-20. \\
\hline
\end{tabular}

Table 2. Description of intervention and comparator using Tidier 


\begin{tabular}{|c|c|c|}
\hline & Rehabilitation for life & Usual rehabilitation and care \\
\hline WHY & $\begin{array}{l}\text { Continuous and progressive rehabilitation as well as early detection of } \\
\text { critical illness and complication during and after hospitalization, will } \\
\text { improve the older adults' physical performance and decrease mortality. } \\
\text { Knowledge empowers the older adult and facilitate a change in mindset } \\
\text { among health professionals. }\end{array}$ & $\begin{array}{l}\text { Activity based rehabilitation restore and } \\
\text { maintain activities of daily living. } \\
\text { The older adults need to regain functions } \\
\text { creates motivation. }\end{array}$ \\
\hline WHAT & $\begin{array}{l}25 \text { rehabilitation session with a physiotherapist over } 12 \text { weeks of these } 5 \\
\text { within two weeks from discharge, is planned. } \\
\text { - } \\
\text { A virtual meeting between physiotherapist in primary and secondary sector } \\
\text { discharge. } \\
\text { - } \\
\text { The suitcase contain knowledge and equipment the older adults need to } \\
\text { take responsibility and perform daily exercises. } \\
\text { Health professionals participate in a workshop } \\
\text { - } \\
\text { Early detection of critical illness and complications performed day } 3 \text { after } \\
\text { discharge. }\end{array}$ & $\begin{array}{l}\text { The older adult general amount of } \\
\text { rehabilitation is appoximatly } 1-2 \\
\text { rehabilitation sessions a week for } 6-8 \\
\text { weeks. } \\
\text { Care has to be prescribed. }\end{array}$ \\
\hline $\begin{array}{l}\text { WHO } \\
\text { PROVIDE }\end{array}$ & Physiotherapists, nurses, and Social- and Health assistants. & $\begin{array}{l}\text { Physiotherapists, nurses, social- and Health } \\
\text { assistants }\end{array}$ \\
\hline HOW & Face to face, virtual meetings and App & Face to face \\
\hline WHERE & Ortho-geriatric ward, the patients home, and in the rehabilitation centers. & $\begin{array}{l}\text { Ortho-geriatric ward, the patients home, and } \\
\text { in the rehabilitation centers. }\end{array}$ \\
\hline $\begin{array}{l}\text { WHEN and } \\
\text { HOW } \\
\text { MUCH }\end{array}$ & $\begin{array}{l}\text { Week } 1 \text {-2 after discharge: } \\
\text { - Five training sessions with a physiotherapist, duration up to } 60 \text { minutes. } \\
\text {-One virtual meeting duration } 30 \text { minutes } \\
\text {-vial measurements, duration up to } 45 \text { minutes. If necessary one follow-up } \\
\text { meeting with the municipal emergency nurse assessment, duration up to } 45 \\
\text { minutes. } \\
\text { Week } 3 \text { - week } 12 \text { after discharge: } \\
2 \text { weekly rehabilitation session with a duration up to } 45 \text { minutes is } \\
\text { planned. }\end{array}$ & $\begin{array}{l}\text { During admission: rehabilitation in the } \\
\text { ortho-geriatric consist of a daily session } \\
\text { with a physiotherapist duration of } 30 \\
\text { minutes. } \\
\text { Week } 1 \text { after discharge: } \\
1 \text { rehabilitation session duration up to } 45 \\
\text { minutes. } \\
\text { Week } 2-8 \text { after discharge: } \\
-1 \text { or } 2 \text { weekly sessions of rehabilitation } \\
\text { duration } 45 \text { minutes. }\end{array}$ \\
\hline TAILORING & $\begin{array}{l}\text { Patients with a CAS score } \geq 4 \text { receive rehabilitation at a rehabilitation } \\
\text { center. Progression follows the national guidelines }(11) \text {. }\end{array}$ & $\begin{array}{l}\text { The patient rehabilitate at home or at a } \\
\text { rehabilitation center, pending on an } \\
\text { individual assessment. }\end{array}$ \\
\hline
\end{tabular}

Table 3. forms and procedures adapted from the SPIRIT 2013 explanation and elaboration: guidance for protocols of clinical trials (16) 
Post allocation

\begin{tabular}{|c|c|c|c|c|c|c|c|c|c|c|}
\hline \multicolumn{11}{|l|}{ Time point } \\
\hline Activity/assessment & $\begin{array}{l}\text { Enrollment - } \\
t_{1}\end{array}$ & $\begin{array}{l}\text { Allocation } \\
0\end{array}$ & $\begin{array}{l}\text { In- } \\
\text { hospital } \\
t_{1}\end{array}$ & $\begin{array}{l}2 \\
\text { weeks } \\
t_{2}\end{array}$ & $\begin{array}{l}4 \\
\text { weeks } \\
t_{3}\end{array}$ & $\begin{array}{l}8 \\
\text { weeks } \\
t_{3}\end{array}$ & $\begin{array}{l}12 \\
\text { weeks } \\
t_{4}\end{array}$ & $\begin{array}{l}6 \\
\text { months } \\
t_{5}\end{array}$ & $\begin{array}{l}12 \\
\text { months } \\
t_{6}\end{array}$ & event \\
\hline Eligibility screen & $x$ & & & & & & & & & \\
\hline Informed consent & $x$ & & & & & & & & & \\
\hline Allocation & & $x$ & & & & & & & & \\
\hline Demography & & & $X^{*}$ & & & & & & & \\
\hline TUG & & & $X^{*}$ & & & $x$ & $x$ & $x$ & & \\
\hline CAS & & & $x$ & & $x$ & & & & & \\
\hline Barthel-20 & & & $x$ & & & $x$ & $x$ & $x$ & $x$ & \\
\hline NMS & & & $x$ & & & $x$ & $x$ & $x$ & $x$ & \\
\hline HGS & & & $X^{*}$ & & & $x$ & $x$ & $x$ & $x$ & \\
\hline $30 \mathrm{~s}-\mathrm{CST}$ & & & $x^{\star}$ & & & $x$ & $x$ & $x$ & $x$ & \\
\hline EQ5D & & & $x$ & & & $x$ & $x$ & $x$ & $x$ & \\
\hline CPF & & & $x$ & & & $x$ & $x$ & $x$ & $x$ & \\
\hline VRS & & & $x$ & $x$ & $x$ & $x$ & $x$ & $x$ & $x$ & \\
\hline PAM & & & $X^{\star}$ & & & $x$ & $x$ & $x$ & $x$ & \\
\hline BFI & & & & & & $x$ & $x$ & $x$ & $x$ & \\
\hline Care & & & $x$ & $x$ & & & & & & \\
\hline Co-morbidity & & & $x$ & & & & & & & \\
\hline Bioimpedance & & & $x$ & & & & $x$ & & & \\
\hline Operation & & & $x$ & & & & & & & \\
\hline Reoperation & & & & & & & & & & $x$ \\
\hline Re-admission & & & & & & & & & & $x$ \\
\hline Mortality & & & & & & & & & & $x$ \\
\hline
\end{tabular}

TUG, Timed Up and GO. CAS, Cumulated Ambulation Score. Barthel-20, Barthel 20 item index. NMS, New Mobility Score, 30s-CST, 30 second Chair Stand Test. EQ5D, EuroQol-5 domain. CPF, Composite Physical Function. HGS, Hand Grip Strength. VRS, Verbal Rating Scale. BFI, Brief Fatigue Inventory. Care covers early detection of illness, complications and pain management e.g. blood pressure, pulse, respiratory frequency, saturation, consciences, temperature and saturation.

*marked will be measured at discharge

\section{Figures}




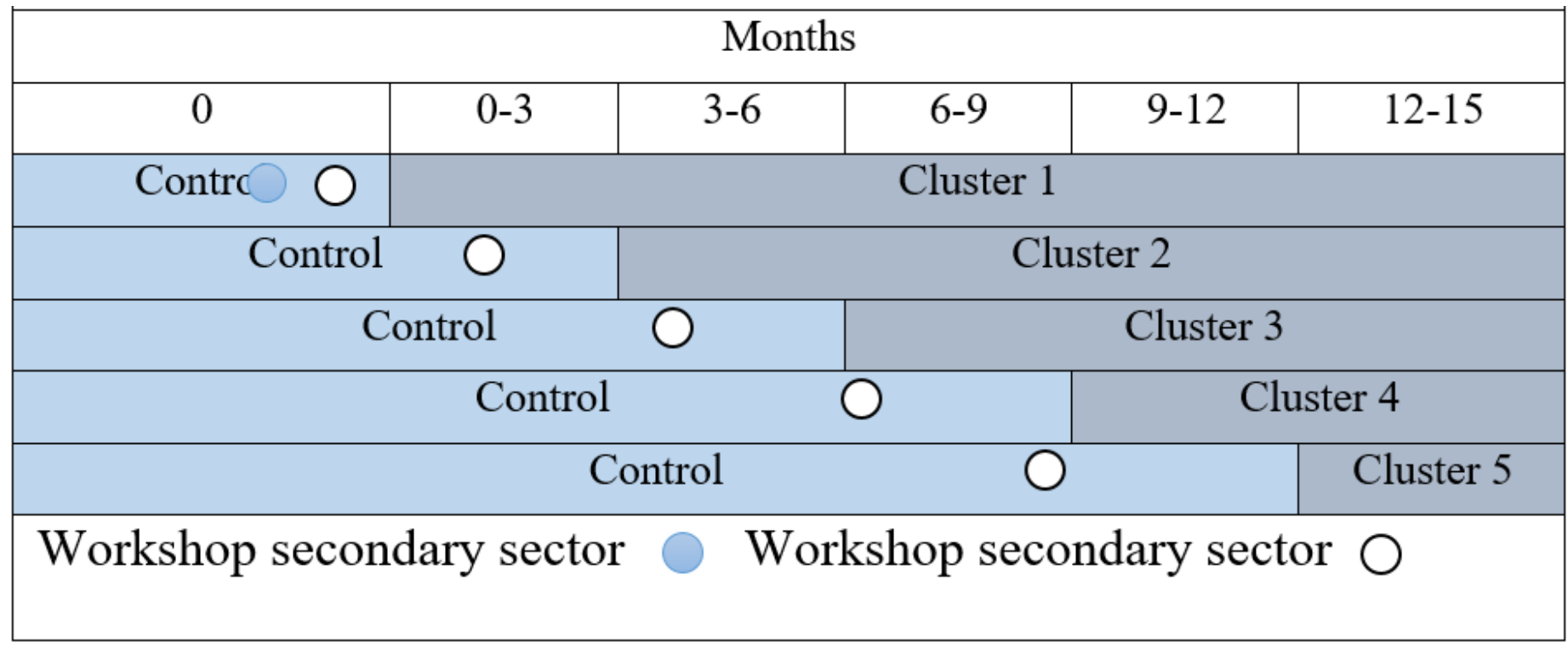

Figure 1

Overview of the clusters and the cross over from control to intervention.

\section{Supplementary Files}

This is a list of supplementary files associated with this preprint. Click to download.

- completedSPIRITAdditionalfile.docx 